\title{
Reply to the Readership regarding Ilgren \& Hoskins (2018) Anthophyllite Mesothelioma Articles
}

\author{
Prof. E. B. Ilgren, MA (Oxford), MD, D.Phil. (Oxford), FRCPath (London) \\ Diplomate, American Boards of Pathology (Chicago) \\ Formerly, Pathologist to Her Majesty's Coroner for Oxford \& \\ Faculty, Biological Agricultural Sciences, Biochemistry Sub-faculty \\ University of Oxford
}

Visiting Professor of Neuropathology and

Expert Investigator in Environmental Neurotoxicology

University of Chile de la Norte (Tarapaca) (UTA)

Avenido Ingeniero Raúl Pey 2911

Arica, Chile 1000000

Chilean Mobile: 95359

Chilean Land Line 0056582215420 x124

Skype 0012156422683

dredilgren@aol.com

The Readership of our four anthophyllite mesothelioma papers has shown great interest in our work. The purpose of this paper is to answer several of their queries and elaborate on a few additional points. The most basic question has been why anthophyllite does not appear to induce mesothelioma in man. The primary reason relates to fiber width.

Wagner et al [1960] showed a clear causal association between asbestos and mesothelioma causation due to South African crocidolite. By 1994 tens of thousands of mesotheliomas had been recorded due to crocidolite. By contrast, the first alleged Finnish anthophyllite asbestos mesothelioma was recorded in 1986. This was reported in 1994 by Meurman, Karjalainen et al nearly 30 years after Wagner et al's sentinel discovery. Meurman [1994] commented upon this glaring anomaly and alluded to the role of anthophyllite's increased fiber width as its cause. Twenty- five years later, our four anthophyllite papers [Ilgren and Hoskins, 2017a, b; 2018 c, d] confirmed precisely what Meurman, Karjalainen et al [1994] surmised ${ }^{1}$. In summary, we do not believe the epidemiological data produced to date confidently confirm anthophyllite related mesotheliomas in humans.

Regarding the Finnish story, eight cases appear to be under discussion. Four were reported by Karjalainen et al [1994] and four more by Nyas et al [2017]. Karjalainen et al [1994] presented some case specific data. However, Nynas et al had no case specific data for the four "new" cases. I therefore went to Finland in 2015 to see what underlying case specific data for all eight cases could be obtained from the Finnish Experts in charge of the cohort. I found that three of the four cases reported by Karjalainen et al [1994] were diagnostically unstable. Thus, case number 2, the 'sarcomatous pleural mesothelioma' diagnostically questioned by Karjalainen et al [1994] had been removed ${ }^{2}$. Dr. Heinrich Wolf, the FIOH senior pathologist said [pers com 2015] the other sarcomatous mesothelioma reported by Karjalainen et al [1994] (Case 3) and the epithelial peritoneal mesothelioma in Karjalainen et al [1994] (Case 1) were also diagnostically unstable since the diagnostic tools available in 1986 and 1989 were not able to confidently confirm the alleged diagnoses.

Epidemiological Stability: Professor Oksa [pers com 2018] said 'epidemiological studies are key to the assessment of causality between anthophyllite asbestos and mesothelioma. ... and all participants must be

\footnotetext{
${ }^{1}$ Our Bolivian crocidolite papers [Ilgren et al, 2012a, b, c; 2015; van Doren et al, 2012] on the theme of increased fiber width confirm the Finnish findings.

${ }^{2}$ This is evidenced by the total of 3 cases in the tabular data from 1967 to 1992 shown to me in September 2015 at a joint meeting in Helskini with Professor Oksa, Tuomi, Paakala, and Wolf and by the same data shown in table 3 of Nynas et al [2017].
} 
examined with the same level of accuracy". I totally agree. However, the epidemiological studies were not conducted with the same level of accuracy. Here are several examples why.

1. The four 'new' cases were based on 'group level' data ${ }^{3}$, whilst the four reported by Karjalainen et al [1994] had some case specific information.

2. The large number of workers studied by Nurinimen [1972] in the first epidemiological study of the Paakilla workers in the cohort from 1936 to 1967 were apparently excluded by Nynas et al [2017] ${ }^{4}$. Nynas et al [2017] thus based their study on 734 Paakilla miners and millers whilst Nurinimen [1972] included 1495 employees ${ }^{5}{ }^{6}$ who worked from 1936 to 1968. It is impossible to understand why Oksa and Nynas et al [2017] totally dismiss Nurinimen's [1972] study. Nurinimen said in 2015 said his earlier work was very much a part of the cohort $^{7}$

3. Nurinimen's [1972] study does not refer to 'miners'; only 'factory' workers whilst Nynas et al 2017 per Oksa (pers com) said "factory" workers were those who worked in the 'mill', not the 'mine'. If this is so, it is not clear if Nurinimen [1972] only examined the 'millers' but not the miners.

4. Finally, further confusion is engendered trying to reconcile the different number of workers studied by Karjalainen et al $1994(\mathrm{n}=999)$, Panu [2011] ( $\mathrm{n}=752)$ and Nynas et al [2017] ( $\mathrm{n}=734)$. (supplemental information available).

Conflicts of interest: We were not paid to write up the publications. I had limited corporate funding to prepare for and undertake the Finnish trip. However, the FIOH team faced pending closure and large planned lay-offs because of funding shortages in $2015^{8}$. They never disclosed that they, even as a 'governmental' institution, had been funded significantly by QAMA and Partek for years. ${ }^{9}$ Thus, the first cohort study of the Paakilla workers by Nurinimen [1972] (and his study of other sources of asbestos related mesothelioma in Finland [Nurinimen, 1975] were funded by QAMA. The Chief archivist of the FIOH said the Finnish Government could not afford to fund the FIOH so the Paraisten Kalki company paid for many FIOH's services. The funding sources for Ahlman [1973], Meurman et al [1979, 1994], Karjalainen et al [1994] and Nynas et al [2017] were also not stated whilst Nynas et al [2017] simply said they had no 'conflicts of interest' to declare. Professor Huuskonen was also a witness acting on behalf of Oy Partek in a legal proceeding ${ }^{10}$

In addition, the US Congress approved a request from the US NIOSH under 'Executive Order" not subject to

\footnotetext{
${ }^{3}$ Base on the detailed review of correspondence and meetings with Oksa and his team from November 2013 through 2016 [available upon request]

${ }^{4}$ Allegedly since 1967 was the first date an automatic data retrieval system was used (Pukkalla 2015 pers com).

${ }^{5}$ A total number of 1495 were employed in the factory during the study period. The cohort included 1030 workers who had been on the factory's payroll a minimum of three months and whose person-years could be counted. Eighty-one per cent of them were male."

${ }^{6}$ Nurinimen's [1972], Table 1 therefore indicates that the total person years of follow up by the end of his study in 1968 was 22,011 (17,554 for males and 4416.5 for females) which appears to be more than the number examined by Nynas et al [2017] as of 2012.

7 "My first work assignment as a biostatistician at FIOH had to do with asbestos-related diseases. The author's mortality study revealed risks of past exposure to asbestos decades ago [Nurinimen, 1972]. According to the life table analysis, excess deaths from asbestosis and lung cancer shortened the expected length of lives of 15-to-24-year-old workers at an open quarry and mine of anthophyllite asbestos in Eastern Finland by over two years. In older age groups the average loss was in relative terms greater, eight per cent." It is difficult to believe Nurinimen's [1972] work had to be 'discarded' on the basis of ascertainment method. The Finnish Registry tracing record system is one of the most complete and accurate in the world. It might take longer to manually obtain the data but this would hardly seem to justify discarding Nurinimen's entire 1972 effort.

8 "They are making 200 of us redundant (we are 680 ). Wednesday, 16 of our team (about 50 persons) got a message that their efforts are not needed anymore. In the last week of this month the rest of us will know if we still have a job or not. I'm quite confident because the library is running with very small crew, I don't believe that they close the library totally" [Halonen to Ilgren, 16 November 2015]."

${ }^{9}$ When I asked Mr. Keijo Halonen why the exposure conditions at Paakilla were not under better control saying: "I was under the impression that the mines and factories were annually inspected by the FIOH [Ilgren to Halonen, 4. November 2015 13:50]", he then wrote saying: "I suppose that the reason why there is no mention about the FIOH mining inspections is that they never happened or that they were declared secret because of the conditions in the mines and quarries. The Paraisten Kalkki company had the right to keep the information inside the company because they paid for the service. The institute was in great need of money at that time because the government could not afford funding it and that's why they made many jobs for the companies just for earning the money. Actually, it is the same nowadays again. They are making 200 of us redundant (we are 680). Wednesday 16 of our team (about 50 persons) got a message that their efforts are not needed anymore. In the last week of this month the rest of us will know if we still have a job or not. I'm quite confident because the library is running with very small crew, I don't believe that they close the library totally" [Halonen to Ilgren, 16 November 2015.

${ }^{10}$ Answers to Interrogatories - Section A. III: "Witnesses on behalf of Oy Partek AB" - available on request).
} 
review to provide the FIOH with $\$ 280,000$ US dollars in ca $1994^{11}$ to undertake an international scientific collaboration with the US NIOSH and Russian Institutes to study the health of "Siberian chrysotile miners and millers" ${ }^{12}$. Presumbly, the FIOH was perceived to be an independent institution part of and fully funded by the Finnish Government. The funds were provided in the belief that the study being funded would be of use in protecting the health of American workers. Justification provided for giving the FIOH the funding was based, at least in part, on the idea that "US workers involved in construction operations overseas can be exposed to the Uralasbestos product" (since) "as you know, major US construction companies do not restrict their activities to the United States..."

Moreover, I also tried to get the case specific details myself with the help of the eminent Helsinki University ethnologist, Prof. Hannah Snellman. Initially in 2015 she told me she was able and enthusiastic to do so. However, six months later she wrote to say it was not possible because she was chairing committees which involved central figures from Partek. [Snellman to Ilgren, March 2016].

Failure to Follow Up and Report the Health Status of the Heavily Domestically Exposed Paakilla Miner and Miller Families and the Tapinilla Factory Workers and their Families: The FIOH faced a serious financial crisis in 2015 allegedly precluding further case specific study of the mesotheliomas allegedly due to anthophyllite. I therefore found corporate funds for Oksa and his team to complete the case specific analysis of all of the alleged anthophyllite mesotheliomas in the cohort. However, when I told the FOIH team I had obtained the required funding ${ }^{13}$, they declined the offer saying firstly they would not "put into action the study you propose" [pers com, 2015] and if they decided to do so in the future, would only do so using public funding.

Clearly, the case specific analysis the alleged anthophyllite mesotheliomas was simply not a priority since they had access to "Finish" funding in 2015.

Moreover, the FIOH team overseeing the Paakilla cohort received significant funding in 1994 for other projects that could have been used to follow up and report the health status of the heavily domestically exposed Paakilla miners and millers' families as well as the Tapinilla workers and their families. This is evident from the fact that the FIOH in this time period received significant funding not only to study the health of 20,000 construction

${ }^{11}$ Indeed, senior NIOSH officials were not pleased by the 'US - Finnish Cooperative Agreement' as indicated in a memo from Barbara Brown to Jack Parker re "Benefit to the US: Finnish Coop Ag" (24 August 1994) that read: "Henry talked with Donna Black yesterday and clarified with her what their role was and what Grants role was (in other words, Henry was furious and told Donna that all they had to do was simple clearance with regard to governmental interactions: it was his job to address relevancy, etc). Henry and Oppie plan to keep in close touch. This has never occurred before with similar grants and Henry is concerned that 'something is up' with this one". The matter also apparently initiated a Congressional Inquiry "Subject: Siberian Asbestos" (13 June 95)" per a memo from Robert Castellan to Dick Lemon which read: "Dick: Jack Parker just called from Helsinki. He mentioned that you had contacted him about a Texas Congressman's inquiry regarding the Siberian asbestos project - apparently concerned that the project will have no benefit for American workers or American companies. Jack and I discussed some points worth keeping in mind about potential benefits for America workers. He asked that I pass them along to you". Amongst the three points suggested to support the benefit to American workers included the idea that "US workers involved in construction operations overseas can be exposed to the Uralasbestos product" (since) "as you know, major US construction companies do not restrict their activities to the United States...".

${ }^{12}$ The US PHS funded study was of the Siberian chrysotile miners and millers. Certainly, more Finnish anthophyllite has been used in the United States than Russian chrysotile. It would therefore have been, in theory, more justifiable to fund a study to examine the effect of Finnish anthophyllite on American workers in the United States than the effects of Siberian chrysotile on American workers working 'abroad'. Nonetheless, the FIOH undertook collaboration with Dr. Richard Lemon at the US NIOSH and the Russians to analyze the 'Siberian chrysotile miner - miller cohort'. Dr. Annti Tossavainer, formerly Laboratory Chief of the Department of Industrial Hygiene and Toxicology, as "Program Director", when he was at the FIOH, submitted a Grant application on 12 August 1994 to the US Public Health Services which was received three days later under Federal Identifier U60/CCUO11193-01. The grant was submitted along with Prof. Huuskonen, Drs. Zitting, Roto, and Tuomi and a Mrs. Riala and Mr. Riipinen of the Uusimaa and Tampere Regional Institutes respectively. The grant application was apparently resubmitted under Federal Identifier U60/CCUO11193-02 on 24 April 1995 and this time entitled "Health and Exposure Surveillance of Siberian Asbestos Miners", again signed by Dr. Annti Tossvanien. The application was for US funding to underwrite a three year effort (1 Oct 94 to 30 Sept 97) (Catalogue of Federal Domestic Assistance Number 93-957) signed by Mr. Oppie Byrd "Specialist". A total of $\$ 280,000$ was requested to fund the FIOH undertake this epidemiological study. It was classified as a 'Noncompeting Continuation' application to undertake an 'international scientific collaboration between NIOSH, Russian Institutes and the FIOH' as a 'three year program consisting of exposure evaluations, radiographic screening of exposed workers, lung burden analyses and exchange of scientific information related to asbestos exposure in Asbest, Russia' ... to assist the FIOH in coordinating epidemiological research, surveillance and monitoring, and training to promote the prevention of respiratory diseases among workers exposed to chrysotile asbestos'.

13 "The offer of $\$ 20,000$ still stands. It is simply a very limited case specific analysis of the four or five new cases. Given my discussions with Timo seven weeks ago regarding the potential limitations of the STEM in detecting very thin fibers, it could also possibly involve lung burden work using TEM - XRD on the three old ones as well. Would you please let me know what your current thinking is regarding my proposal to undertake the case specific analysis? I know you are going on holiday in two days but it would seem to be a good time to get your thoughts on the offer." 
workers; to conduct a collaborative study with the Geological service of Finland (GSK) [Nikkarinen al, 2003] to assess the risk of 'environmental' exposure to the very small handful of people living or simply vacationing around Paakilla decades after the mine and mill had been $\operatorname{closed}^{14}$; and from the US NIOSH to study the Siberian chrysotile miners and millers with the Russians and US NIOSH workers.

Ironically, the families of the miners, the millers and the factory workers who incurred horrific exposures were very concerned about their future health as the domestic exposure conditions at Paakilla and Tapanilla were very bad $^{15}{ }^{16}$ This was described in a 1978 Finnish video ${ }^{17}$ interview of Paakilla workers and their families. The only statement in the literature on this point said "Para-occupational exposure of the family and the neighborhood and during leisure time work with products containing asbestos are areas of their own" [Huuskonen, 1978]. During my Finnish visit in 2015 Prof. Huuskonen said the issue of domestic exposure had never been looked at. Former Paakilla residents were also very concerned about their own health but never received any information from the FIOSH regarding their level of future risk from the historical exposures (vs) [see Ilgren and Hoskins, 2018]. Thus, whilst the Paakilla families and Tapinilla workers were concerned, the FIOH deemed "domestic exposure "just" an 'area of its own"" [Huuskenon, 1978] and apparently not own of theirs. [also see Ilgren and Hoskins, 2018b]

Surveillance: Nynas et al [2017 said the first periodic health screening for asbestosis was in 1977. However, Huuskonen [1978] and Huuskonen \& Tossavainen [1978] found cases in 1964; the Finnish Register of Occupational Diseases reported asbestosis patients as early as 1938; and the FIOH studies of the health of workers of Paakilla started from the 1950s; of Tapanilla from the 1940s; and of Muijalaand and Pargas from the 1960s, all reporing asbestosis [see Ilgren \& Hoskins, 2018b]. Therefore, health screening for asbestosis and, of course, mesothelioma, started long before 1977 making it more than likely that the FIOH and leading Finnish physicians were aware of the level of disease and the terrible hygiene conditions largely without regulation that were responsible for the problem. Importantly, despite the large amount of asbestosis, no mesotheliomas due to anthophyllite as late as 1978 were found [Huuskonen, pers. comm., 2015].

Commercial Amphibole Asbestos as an Alternate Causation Explanation: Some readers believe crocidolite, amosite and / or tremolite are not possible alternate causes of the three mesotheliomas reported by Karajllenen et al [1994] with lung burden analysis and, by proxy, the other alleged cases for which no case specific information has been published to date. I disagree.

1. According to Tuomi [per com 2015] STEM cannot exclude very thin crocidolite fibers in the three cases reported by Karajllenen et al [1994] with lung burden with certainty ${ }^{18}$ and such fibers could have been missed.

2. The one diagnostically acceptable case (case 4 ) was actually never subjected to lung burden ${ }^{19}$

3. Amongst the three cases subjected to lung burden, only 30 fibers less than $0.1 \mathrm{u}$ in diameter were found. Thus, if more fibers were examined for fiber type in this size range (a range within which more than $85 \%$ of South African or Western Australian crocidolite asbestos fibers are found) crocidolite might have been detected.

4. Chatfield [pers com 2018] said the lung burden analysis methodology applied in Karylenen et al [1994] was problematical in that "There also appeared to be no specification of the minimum fibre length to be included in the fiber counts raising the question as to whether the thinnest fibers would be counted by ISO. The fiber counts

\footnotetext{
${ }^{14} \mathrm{~A} 2006$ Finnish video (available on request) shows men in space suits ridiculously vacuuming the bottom of the lake and the beach front near Paakilla as if such exposures could be of risk to anyone. The idea that today's summer residents were more deserving to be studied than the families of the workers historically exposed to horrific fiber levels that left many of their fathers and mothers dead from asbestosis and lung cancer at an early age is utterly absurd. The present environmental conditions could never create a true health hazard. Claims of risk of asbestosis and mesothelioma from what remains today are not founded. I have seen the area. Present day residents with no historical exposure link to the early mining and milling activities are simply not at risk. Claims to be contrary are also unfounded.

${ }^{15}$ Matti Auvenin, a 55-year old, corporate executive living in Kuopio was born and raised in Paakilla. His wife was the Professor of Oncology at the University of Kuopio medical school. They had a summer cottage on the lake $2 \mathrm{kms}$ from Paakilla and very kindly invited me to spend the day with them there in October 2015 touring the area. This included the mine site, factory and surrounding area and were significantly concerned about their health from domestic and environmental exposure but never received any such information.

${ }^{16}$ Nurinmen 2015 also remarks on conditions in the asbestos plant he worked in that were sufficient to have 'suffocated' the manager of a Finnish asbestos company from asbestosis.

${ }^{17}$ Official English Translation of the video available on request

${ }^{18}$ Karjalainen et al. [1994] said careful analyses by transmission electron microscopy showed all mineral fibres detected in the lungs of the patients were anthophyllite asbestos. No crocidolite, no amosite, no tremolite, no chrysotile was detected. Also thin fibres were found; widths of anthophyllite fibres ranged from 0.05 to 1.5 micrometer with a median of about 0.35 micrometer.

${ }^{19}$ It is also not clear if case 4 was one of the pleural cases that also invaded the abdominal cavity [Karyllenin et al, 1994, pg 213, col. 2, para 3]. Whilst this can occur with pleural mesothelioma, it is not commonly seen nor is invasion of the pleura from peritoneal mesotheliomas.
} 
made in TEM mode at a magnification of 16,000 measuring the length and width of each fiber in STEM mode could create a $0.8 \mathrm{~mm}$ wide image with reasonable contrast say for a $0.05 \mathrm{u}$ wide fiber. However, when Tuomi's paper was accepted in 1991, energy dispersive x-ray detectors were not very sensitive to x-rays and for thin fibers, the x-ray count could be very slow making it, on occasion, difficult to obtain a spectrum with a statistically valid x-ray peak for sodium". Since the identification of sodium is required for the identification of crocidolite, crocidolite may have been missed if statistically valid $\mathrm{x}$ ray peaks for sodium could not have generated and, given the comments made by Dr. Chatfield, this was a possibility during the time in which Karylenen et al's [1994] studies were done.

5. The use of crocidolite was documented at the three historical anthophyllite asbestos factories outside of Helsinki [Muijala, Tapanilla, and Pargas] [Partek’s Ans. to Interogs [Sup. Ct. of Delaware].

6. Some Readers believe the level of crocidolite and amosite consumption in Finland was too small to impact mesothelioma causation ${ }^{20}$. However, consumption data are not accurate indicators of mesothelioma causation. They do not reflect fiber potency. That has been repeatedly demonstrated by lung burden analysis in situations where a single fiber type such as chrysotile was thought to be the only fiber to which workers were being exposed. This was the case, for example, for many years for the Quebec chrysotile miners and millers and the Charleston and Rochdale chrysotile textile workers. This led to the false conclusion that chrysotile was the cause of the observed mesotheliomas. Lung burden studies showed highly elevated discriminatory levels of amphibole asbestos in the lungs of the mesothelioma cases that clearly demonstrated their cause was not chrysotile. [Green et al, 1997; Pooley, 1991].

7. The possibility that crocidolite was used at Paakilla was clear from our own finding of crocidolite in the factory wall board at Paakilla [Ilgren and Hoskins 2017a]. ${ }^{21}$

8. Many lung burden studies done by the Finnish scientists found significant amounts of crocidolite and / or amosite in Finnish urbanites and workers [Nurimen, 1975; Karajelenen et al, 1993 a,b; 1994 b; Tuomi, 1992; Tuomi et al, 1989, 1991; Uibu et al., 2009; Tossavainen et al., 1994; Vilkman et al., 1993].

9. Some of the anthophyllite fibers could have been cleavage fragments as the dimensional profile data given in Karjalainen et al [1994, Table 2] suggest 10 to $15 \%$ might be non-asbestiform on the basis of smaller aspect ratios and greater widths, cleavage fragments lacking biologically activity [Ilgren et al, 2004].

\section{Bibliography (All materials cited from Siberian Chrysotile Miller FOIA available upon request**):}

Ahlman, K., Partanen, T. J., Rintala, E., \& Wiikeri, M. [1973]. Anthophyllite mining and milling as a cause of asbestosis. Biological effects of Asbestos, IARC Scientific Publications No.8 IARC - Lyon, France: pp. 165-168.

Green, F, Harley, R., Vallyathan, V., Althouse, R. Fick, G, Dement, J, and Pooley, F [1997] Exposure and mineralogical correlates of pulmonary fibrosis in chrysotile asbestos workers. Occup. Environ. Med. 54: $549-559$.

Ilgren, E and Hoskins, J [2019] Anthophyllite Asbestos: The Role of Fiber Width in Mesothelioma Induction. Part 4: Mechanistic Considerations regarding the Failure to Observe Anthophyllite Asbestos Mesotheliomas in Humans. Environment and Pollution. Vol. 8, No. 1; 2019. ISSN 1927-0909 E-ISSN 1927-0917.

Ilgren, E and Hoskins, J. [2018] Anthophyllite Asbestos: The Role of Fiber Width in Mesothelioma Induction. Part 2: Further Epidemiological Studies of Occupational, Domestic and Environmental Exposure to Finnish Anthophyllite Asbestos. Environment and Pollution; Vol. 7, No. 1; pp. 24 - 35. ISSN 1927-0909 E-ISSN 1927-0917.

Ilgren, E and Hoskins, J. [2018a] Anthophyllite Asbestos: The Role of Fiber Width in Mesothelioma Induction. Part 1: Epidemiological Studies of Finnish Anthophyllite Asbestos. Environment and Pollution; Vol. 7, No. 1; pp. 9 - 23. ISSN 1927-0909 E-ISSN.

\footnotetext{
20 "The highest consumption of all asbestos in Finland was about 12000 tons a year in the mid-seventies and total cumulative consumption has been estimated at the level of more than 300000 tons, from which 120000 tons (about 40\%) was domestic anthophyllite (Rantanen et al. 2014). During the past 30 years, about 1000 mesotheliomas have been (on the basis of careful scrutiny) compensated as occupational diseases in Finland. In numerous cases, the mesothelioma patients have been exposed to anthophyllite alone or in combination with chrysotile as verified by work histories and lung tissue analyses."

${ }^{21}$ Samples were taken with the Auvenins (also see above) who had lived in the area for decades and knew where the samples were taken from.
} 
Ilgren, E and Hoskins, J. [2019] Anthophyllite Asbestos: The Role of Fiber Width in Mesothelioma Induction. Part 3: Studies of American and Japanese Anthophyllite Asbestos - Additional Supportive Evidence Environment and Pollution; Vol. 8, No. 1; ISSN 1927-0909 E-ISSN 1927-0917

Ilgren, E, Ramirez, R, Claros, E, Fernandez, P, Guardia, R, Dalenz, J, Kamiya, Y, and Hoskins, J [2012a] Mesothelioma Induction and Threshold - Bolivian Crocidolite: Epidemiological Evidence from Bolivia Mesothelioma Demography and Exposure Pathways. Annals Resp Med. - Online first.

Ilgren, E, Van Orden, D, Lee, R, Kamiya, Y and Hoskins, J [2012b] Further evidence for Fiber Width as a Determinant of Mesothelioma Induction and Threshold - Anthophyllite, Bolivian Crocidolite and Cape Crocidolite. Annals Resp. Med. - Online first.

Ilgren, E, Van Orden, D, Lee, R, Kamiya, Y and Hoskins, J [2012c] Environmental 'Low dose' Mesotheliomas and their Relationship to Domestic Exposures - Preliminary Report. Environment and Pollution. 3: 48-54.

Ilgren, E, Van Orden, D, Lee, R, Kamiya, Y and Hoskins, J [2015] Further Studies of Bolivian Crocidolite -Part IV: Fibre Width, Fibre Drift and their relation to Mesothelioma Induction. Epidemiology Biostatistics and Public Health 12: 111671 - 1116711

Karjalainen A, Anttila S, Heikkila L, Kyyronen P, Vainio H [1993b] Lobe of origin of lung cancer among asbestos-exposed patients with or without diffuse interstitial fibrosis. Scand J Work Environ Health 1993;19(2):102-107.

Karjalainen A, Vanhala E, Karhunen PJ, Lalu K, Penttila A, Tossavainen A [1994] Asbestos exposure and pulmonary fiber concentrations of 300 Finnish urban men. Scand J Work Environ Health 1994b;20(1):34-41.

Karjalainen, A. Anttila, MD, L. Heikkila, MD, P. Karhunen, MD, and H. Vainio, MDAsbestos Exposure Among Finnish Lung Cancer Patients: Occupational History and Fiber Concentration in Lung Tissue. American Journal of Industrial Medicine 23:461-471 [1993a]

Meurman, L. O., Kiviluoto, R., \& Hakama, M. [1974]. Mortality and morbidity among the working population of anthophyllite asbestos miners in Finland. British J Indust Medicine, 31, 105-112.

Meurman, L. O., Pukkala, E., \& Hakama, M. [1994]. Incidence of cancer among anthophyllite asbestos miners in Finland. Occup Environ Med, 51(6), 421-425. https://doi.org/10.1136/oem.51.6.421

Nurinmen. [2015]. Working-life expectancy in Finland: trends and differentials 2000-2015 A multistate regression modeling approach - https://www.etk.fi/wp-content/uploads/2015/10/raportti\%2003\%202012\%20nettiin.pdf

Nurminen, M. [1972]. A study of the mortality of workers in an anthophyllite asbestos factory in Finland. Scandinavian Journal of Work Environment Health, 9, 112-118.

Nurminen, M. [1975]. The epidemiologic relationship between pleural mesothelioma and asbestos exposure. Scand J Work Environmental Health, 1, 128-137. https://doi.org/10.5271/sjweh.2854

Nynäs, P., Pukkala, E., Vainio, H., \& Oksa, P. [2017]. Cancer Incidence in Asbestos-Exposed Workers: An Update on Four Finnish Cohorts. Safety and Health at Work 8 [2017] 169e174. https://doi.org/10.1016/j.shaw.2016.11.003

Oksa, P. [2013]. Well-being through Work. Power point presentation: Epidemic of Asbestos-induced diseases in Finland. Past, Present and Future. Delivered 07/12/2011. Finnish Institute of Occupational Health www.ttl.fi.

Paakkilan Video. [1978]. http://yle.fi/aihe/artikkeli/2010/08/26/paakkilan-asbestikyla

Rantanen J, Lehtinen S, Huuskonen M, Oksa P, Tossavainen A, Tuomi T, Vainio H. Prevention and management of asbestos-related diseases in Finland. FIOH, Helsinki 2014 https://www.julkari.fi/bitstream/handle/10024/135520/Prevention\%20and\%20Management\%20of\%20Asbe stos-Related\%20Diseases\%20in\%20Finland.pdf?sequence $=1$

Tuomi, T. [1992]. Fibrous Minerals in the Lungs of Mesothelioma Patients: Comparison Between Data on SEM, TEM, and Personal Interview Information. American Journal of Industrial Medicine 21:155-162.

Tuomi, T. Huuskonen, M., Tammilehto, L., Vanhala, E, Virtamo. M. [1991]. Occupational exposure to asbestos as evaluated from work histories and analysis of lung tissues from patients with mesothelioma. British Journal of Industrial Medicine 48:48—52. 
Van Orden, D, Lee, R, Zock, M, Sanchez, M, Ilgren, E [2012] Evaluation of Airborne Crocidolite Fibers at an Asbestos-Cement Plant. Annals Resp. Med. - Online first.

\section{Copyrights}

Copyright for this article is retained by the author(s), with first publication rights granted to the journal.

This is an open-access article distributed under the terms and conditions of the Creative Commons Attribution license (http://creativecommons.org/licenses/by/4.0/). 